\title{
Probiotics What You Missed
}

\author{
*Aziz Koleilat \\ Pediatric department, Makassed University General Hospital, Lebanon
}

Submission: July 20, 2017; Published: July 31, 2017

*Corresponding author: Aziz Koleilat, Pediatric department, Makassed University General Hospital, Lebanon, Tel: 009613 231717;

Email: drkoleilat@hotmail.com

\section{Introduction}

The 20th century was the age of antibiotics and corticoids, the 21st century will be the age of probiotic and immunity [1].

Probiotic is now worldwide, one of the main interests in the field of medicine. Many people use probiotic, prescribe it and recommend it. Millions of articles are produced as reviews and trials. Studies are done all over the world; symposia and congresses are very active in this field, even societies are formed to revive the probiotic kingdom. Commercially, probiotics have been over used and recommended by many companies. Probiotics became a must in infant feeding especially milk formulas. So what is probiotic and how do we have to approach this phenomenon?

Probiotics are defined as "live micro-organisms which, when administered in adequate amounts, confer a health benefit on the host" [2]. Probiotics are viable microbial dietary supplement. They are living micro-organisms used as food additives having a beneficial effect on the host by improving digestion and intestinal hygiene $[3,4]$.

\section{Criteria for Probiotics}

In order to use viable bacteria, there are some criteria. The bacteria must be safe for consumption such that they are not pathogenic and do not carry antibiotic resistance genes and do not degrade intestinal mucosa or conjugate for bile acids. They should survive intestinal transit (must be acid and bile tolerant), and be able to adhere to mucosal surface and colonize the intestine. They must also produce antimicrobial substances and antagonize pathogenic bacteria and be stable during processing and storage [5].

\section{Myths and Misconceptions}

There are many misconceptions and myths regarding probiotics. Not all probiotic supplements are the same. They could have different effects on health and cannot replace medications. Not all food and supplement labels provide accurate microbe counts. As for yogurts, they contain probiotics but are not generally a good source of probiotics. The best probiotics are kept in the fridge is not always true and lyophilisation does not ensure that the probiotics remain viable at room temperature. Probiotics should not be used while taking antibiotics is not necessary true [6].

Another common misconception is that probiotics must always colonize the intestinal tract to exert their effects. Some probiotics such as Bifidobacterium longum and Bacteroides become part of the human intestinal microflora, whereas others such as Lactobacillus casei and B. animalis may not, they may stay and adhere from few days to weeks and then are excreted [7]. Non colonizing probiotics indirectly exert their effects either in a transient manner as they pass through or by remodeling or influencing the existing microbial community [8].

\section{Safety of Probiotics}

Are probiotics safe? Do they have side effect on the person using them? Do they have adverse effect on infants and children? These questions come to every mind whenever we are using probiotic for long time. Infection is the first to come to our mind. In the literature there are cases of infection such as endocarditis or bacteremia [9]. Liver abscess caused by lactobacillus rhamnosus was also reported [10]. A review of 200 cases of lactobacillus infection between 1950-2003 revealed 114 cases of bacteremia with mortality rate $32 \%$. All patients had significant morbidity including malignancy, 62 cases had endocardidtis with mortality rate $22.9 \%$ [11].

Several attempts have been made to evaluate the factors that predispose severely ill patients to infection by probiotics, but statistical analysis is lacking and the number of cases is very small to permit the drawing of any firm conclusion associated with endocarditis and bacteremia [11]. Lactobacillus was also associated with other infections including meningitis, peritonitis, and abscesses [9]. 


\section{Anatomy Physiology \& biochemistry international journal (APBIJ)}

Probiotics given to people with severe underlying disease may cause systematic infection as bacteremia and fungemia [12]. Bacteremia was reported in premature babies with shortgut syndrome [13]. Probiotics have been shown to be safe in immunocompetent hosts in an outpatient setting. Nevertheless, administration of probiotics to immunocompromised, chronically ill, hospitalized patients with GI disorders and indwelling catheters may predispose to probiotic sepsis since probiotics may increase translocation of bacteria into the bloodstream [14]. The use of probiotics during pregnancy, in neonates, and in children has not been associated with any adverse immunologic effects [12]. There are other effects than infection. Metabolic and enzymatic effect: theoretically probiotics may have some effect on metabolism of bile salts and mucous (not yet reported). Immunological effects: Immune deficient patient ingesting large amounts of certain probiotics can lead to relapse of autoimmune reactions.

Gene Transfer: Genetically modified probiotics used may harbor antibiotic resistant genes. The risk would be in transferring antibiotic resistance genes to the host. For example, $\mathrm{L}$ reuteri and L plantarum have been found to carry such genes [15].

\section{Efficacy of Probiotics}

Probiotics might not be effective in pancreatitis [16] Probiotics might not be a treatment for asthma. A review stated that trials of the effect of probiotics on asthma are limited and show conflicting results [17]. Interestingly, reduced microbial diversity was associated with diseases such as Crohn's disease and eczema in early life $[18,19]$. Hence, one of the actions of probiotics might be to restore microbial diversity in dysbiosis.

As with diseases, most probiotics tested to date are more effective than placebo in inducing or maintaining inflammatory bowel disease remission. There is good evidence to support the efficacy of S. boulardii and LABs and the combination of the two for antibiotic associated diarrhea, VSL\#3 for pouchitis, and B. infantis 35624 for irritable bowel syndrome [14]. Probiotics reduce the duration of symptoms in acute infectious diarrhea [14]. Probiotics, including E. coli Nissle 1917, LGG, and VSL\#3 are as effective as standard therapy (mesalamine) in inducing or maintaining remission in ulcerative colitis or Crohn's disease [14].

\section{Probiotic Dose}

Different brands of probiotics can contain one to 10 billion colony-forming units (CFUs). As for dosage, a probiotic with one to two billion CFUs is recommended to maintain a healthy digestive tract. However, if a person is taking antibiotics or has symptoms of a bacterial imbalance such as diarrhea, he/she can take a probiotic with up to 10 billion CFUs until the problem is resolved. In order to maintain microorganism balance, a probiotic of one to two billion CFUs daily or every other day could be taken. To correct a problem (dysbiosis), probiotics containing 10 billion CFUs could be taken every day for up to two weeks [20].

Regarding the dose of probiotics for neonates, probiotic supplementation in infants should be done carefully, especially those who are preterm because preterm infants have impaired immune system, poor nutrition, and frequent exposure to harmful microorganisms. It is recommended that: Neonates (less than 32 weeks of gestation): be given $3 \times 10^{9} \mathrm{cfu} /$ day extremely low birth weight infants: be given $1.5 \times 10^{9} \mathrm{cfu} /$ day until they reach enteral feeds of $50-60 \mathrm{ml} / \mathrm{kg} /$ day. The probiotic dose should be diluted in 1.0 to $1.5 \mathrm{~mL}$ of breast milk or water [21].

\section{Conclusion}

Not all Probiotics have the same action and function since they are specific strains. Probiotics are not absolute treatment; they are mainly adjuvant and could ameliorate inflammation. There are side effects for probiotics such as bacteremia and fungemia. What must be finally resolved are the following: The optimal doses, duration of treatment, comparison of different strains and different probiotics, single versus combination probiotics, combination of probiotics with prebiotics, efficacy of various probiotics in different disease states, safety of probiotics in debilitated patients, and safety in patients with compromised gut epithelial integrity. Where probiotics will lead us? Wait and observe....

\section{References}

1. Koleilat A (2016) Probiotics Nowadays. EC Paediatrics 2(1): 100106.

2. Food and Agriculture Organizationof the United Nations. Evaluation of health and nutritional properties of powder milk and live lactic acid bacteria. World Health Organization; 2001.

3. Fuller R, Gibson GR (1998) Probiotics and prebiotics: microflora management for improved gut health. Clinical microbiology and infection 4(9): 477-480.

4. Roberfroid MB (2000) Prebiotics and probiotics: are they functional foods?. Am J Clin Nutr 71(6): 1682s-1687s.

5. Borchers AT, Selmi C, Meyers FJ, Keen CL, Gershwin ME, et al. (2009) Probiotics and immunity. J Gastroenterol 44: 26-46.

6. Nierenberg C (2017) Don't Be Fooled: 5 Probiotics Myths. 2016.

7. Fontana L, Bermudez-Brito M, Plaza-Diaz J, Munoz-Quezada S, Gil A, et al. (2013) Sources, isolation, characterisation and evaluation of probiotics. Br J Nutr 109(S2): S35-50.

8. Ohland CL, MacNaughton WK (2010) Probiotic bacteria and intestinal epithelial barrier function. Am J Physiol Gastrointest Liver Physiol 298(6): G807-G819.

9. Cannon JP, Lee TA, Bolanos JT, Danziger LH (2005) Pathogenic relevance of Lactobacillus: a retrospective review of over 200 cases. Eur J Clin Microbiol Infect Dis 24(1): 31-40.

10. Rautio M, Jousimies-Somer H, Kauma H, et al. (1999) Liver abscess due to a Lactobacillus rhamnosus strain indistinguishable from L. rhamnosus strain GG. Clin Infect Dis 28(5): 1159-1160. 
11. Borriello SP, Hammes WP, Holzapfel W, et al. (2003) Safety of probiotics that contain lactobacilli or bifidobacteria. Clin Infect Dis 36(6): 775-780.

12. Snydman DR (2008) The safety of probiotics. Clinical infectious diseases. Clin Infect Dis 2: S104-11.

13. Kunz AN, Noel JM, Fairchok MP (2004) Two cases of Lactobacillus bacteremia during probiotic treatment of short gut syndrome. J Pediatr Gastroenterol Nut 38(4): 457-458.

14. Verna EC, Lucak S (2010) Use of probiotics in gastrointestinal disorders: what to recommend?. Therap Adv Gastroenterol 3(5): 307-319.

15. Egervärn M, Roos S, Lindmark H (2009) Identification and characterization of antibiotic resistance genes in Lactobacillus reuteri and Lactobacillus plantarum. J Appl Microbiol 107(5): 16581668.
16. Horst NL, Marques RG, Diestel CF, et al. (2009) Effects of probiotic supplementation on markers of acute pancreatitis in rats. Curr Ther Res Clin Exp 70(2): 136-148.

17. Özdemir Ö (2010) Various effects of different probiotic strains in allergic disorders: an update from laboratory and clinical data. Clin Exp Immunol 160(3): 295-304.

18. Manichanh C, Rigottier-Gois L, Bonnaud E, et al. (2006) Reduced diversity of faecal microbiota in Crohn's disease revealed by a metagenomic approach. Gut 55(2): 205-211.

19. Forno E, Onderdonk AB, McCracken J, et al. (2008) Diversity of the gut microbiota and eczema in early life. Clin Mol Allergy 6(1): 11.

20. Bird B, Recommended Dosage for Probiotics. (2015).

21. Mercola J (2011) Help Knock Out Your Baby's Health Enemies - Use Probiotic Supplements.

\section{Your next submission with Juniper Publishers will reach you the below assets}

- Quality Editorial service

- Swift Peer Review

- Reprints availability

- E-prints Service

- Manuscript Podcast for convenient understanding

- Global attainment for your research

- Manuscript accessibility in different formats ( Pdf, E-pub, Full Text, Audio)

- Unceasing customer service

Track the below URL for one-step submission https://juniperpublishers.com/online-submission.php 